Universidad de Panamá

Instituto de Estudios Nacionales
ISNN 1810-5491

Cuadernos Nacionales

N* 26, 81-87, Enero-Junio, 2020

\title{
Michel Foucault: Discursos y Verdad en la Antigua Grecia ${ }^{1}$
}

Bárbara Carrera ${ }^{2}$

\section{Resumen}

Foucault construye una genealogía de la actividad crítica de la filosofía occidental a partir de la palabra parresía o franqueza, siendo el parresiastés un crítico, que conoce el riesgo de decir la verdad pero tiene el valor de hablar para decirla para ayudar a otras personas a mejorar y a sí mismo. Hace de la praxis política un tema moral, problematiza el límite de la verdad en la democracia, haciendo de la verdad un problema de la relación con los demás y consigo mismo, sino además, toda una problematización de la praxis, de la clase política, como problema ético o doble moral. La parresía está conectada con la libertad, el deber, la verdad, el conocimiento, la subjetividad y la praxis social y política. Distingue dos clases de parresía producto de la praxis en la institución democrática o pública y la practicada por los ciudadanos a nivel privado. Da particular importancia a el cuidado de sí, un cambio de vida a partir de la evaluación de sí mismo, se da en la relación entre dos seres humanos; se trata de convencer a alguien de cambiar su estilo de vida. Esta es la base de la subjetividad moral, por ello, quien cuida de sí mismo es un insurrecto. Foucault ve en la parresía un mecanismo para el análisis de la praxis política en la sociedad democrática, resalta la importancia de la moral como punto de partida para la libertad de expresión y la justicia.

Palabras Claves: parresía política, parresía filosófica, parresía positiva, parresía negativa, verdad, libertad de expresión, democracia, doble moral.

\section{Abstract}

Michel Foucault builds a genealogy of critical activity of western philosophies from the word parrhesia or openness, the parresiastes being a critic, who knows the risk of telling the 1. Recibido 10/17/2019 - Aprobado 11/242019.

2. Profesora del Departamento de Filosofía de la Universidad de Panamá. Email: bcarrera27@hotmail.com 
true but he has the courage to speak to said it to help other people to improve himself. It makes political praxis a moral issue, problematizes the limit of truth in democracy, making the truth a problem of the relationship with others and with itself, but also, a whole problematization of the praxis, of the political class, as an ethical problem or double moral.The parrhesia is connected with freedom and or duty, the true, the knowledge, thesubjectivity and the social and political praxis. It distinguishes two kinds of parrhesia as a result of praxis in the democratic or public institution and that practiced by citizens on a private level. He gives particular importance to the care of himself, is an insurgent. Foucault sees in parrhesia a mechanism for the analysis of political praxis in democratic society, emphasize the importance of morality as a starting point for freedom of expression and justice.

Key words: political parrhesia, philosophical parrhesia, positive parrhesia, negative parrhesia, truth, franknees, freedom of expression, democracy, double standard.

Michel Foucault, filósofo, historiador y psicólogo francés se le conoció como el "filósofo insurrecto" debido a su lucha porque se le diera la palabra a los excluidos, que por tanto tiempo habían sido callados. Discursos y Verdad en la Antigua Grecia, no fue publicada, ni corregida por Foucault. Este texto fue editado en 1985 por Joseph Pearson, estudiante que participó en las conferencias de Foucault. Esta transcripción se hizo a partir de las grabaciones de las conferencias ofrecidas en la Universidad de California en Berkeley (1983). Esta no es considerada una edición científica, aunque sigue fielmente la exposición realizada por Foucault en las conferencias.

Foucault se ve a sí mismo como un arqueólogo, aquello que da cuenta de una forma más profunda de la cultura. No es un "historiador de las ideas", sino "un historiador del Pensamiento", "la historia del pensamiento es el análisis del modo en que un campo aproblemático de experiencia, o un conjunto de prácticas que eran aceptadas sin cuestionarlas, que eran aceptadas sin discusión y debate, incita nuevas reacciones, y produce una crisis en el comportamiento, en los hábitos, las prácticas y las instituciones previamente silenciosos" (2004, p. 109). Su preocupación no es por el origen de las palabras sino por los hábitos y costumbres que hacen funcionar las instituciones, la forma como estos hábitos y costumbres "problematizan" llevando a la crisis a estas instituciones de poder existente. La "problematización" implica que es posible dar una respuesta a una 
cierta situación concreta y específica del mundo. Es la respuesta a la relación entre la cosa problematizada y el proceso de problematización.

En este sentido enfoca Foucault la problematización de la verdad en la tradición filosófica occidental. Distingue entre una tradición "analítica de la verdad" y una tradición "crítica".

La tradición "analítica de la verdad" consiste en:

- Asegurar el proceso de razonamiento para determinar si una afirmación es verdadera sea correcta.

- Importancia para el individuo y para la sociedad de decir la verdad, de reconocer la verdad, de tener gente que diga la verdad.

- Saber reconocer esas personas que decían la verdad.

- Determinar cómo asegurar que una afirmación es verdadera.

La tradición "crítica" de la verdad consiste en:

- La importancia de la verdad

- Quién es capaz de decir la verdad.

- Saber por qué debemos decir la verdad.

Su objetivo es construir una genealogía de la actividad crítica en la filosofía occidental.

La palabra parresía significa franqueza, parresiázomai es hacer uso de la parresía y la parresiastés es alguien que utiliza la parresía o dice la verdad.

El parresiastés es alguien que dice todo cuanto tiene en mente, de forma que quien escucha sea capaz de comprender exactamente lo que piensa el hablante. Muestra lo que cree realmente "yo soy quien piensa esto o aquello". Para los griegos quien conoce y comunica la verdad a los otros debe poseer ciertas cualidades morales que garantizan la posesión de 
esta verdad. Lo que dice el parresiastés es un riesgo, es peligroso para él mismo. El valor del parresiastés está en atreverse a decir algo distinto de lo que se cree, cuyo peligro extremo es la vida o la muerte. El parresiastés es un crítico. La parresía está conectada con la libertad y el deber. Nadie te obliga a hablar y decir la verdad, puede permanecer en silencio, pero se considera un deber hablar y decir la verdad. Foucault ve la Parresía como una de estas prácticas y la define como "una actividad verbal en la que el hablante expresa su relación personal con la verdad y arriesga su propia vida porque reconoce el decir la verdad como un deber para mejorar o ayudar a otras personas y a sí mismo" (2004, p. 44)

El parresiastés hace uso de su libertad y escoge entre: la franqueza o la persuasión; la verdad o la falsedad, o el silencio; el riesgo de muerte o la vida, la seguridad; la crítica o la apatía moral.

La función de la parresía no es mostrar la verdad, sino hacer críticas al interlocutor o hacia uno mismo, pero el que habla está en condición de inferioridad y puede ser castigado.

Se distinguen dos clases de Parresía: una política y otra filosófica (o socrática).

La parresía política, es producto de la institución democrática, se da en el Ágora. Para hacer uso de ella hay que ser ciudadano varón, debe estar entre los mejores ciudadanos y tener ciertas cualidades personales, morales y sociales que garantizan el privilegio de hablar. Las mujeres en su condición de ser oprimidas, los esclavos, los niños y los enajenados no formaban parte de la vida política de la ciudad, por lo tanto, no tenían derechos a practicar la parresía. Si el parresiastés proponía algo que era combatido por la mayoría o revelaba una verdad que amenazaba a la mayoría, arriesgaba su privilegio de hablar libremente y podía ser exiliado para proteger a la asamblea contra la verdad. Con la crisis de las instituciones democráticas griegas se da la "problematización" de la parresía: ¿quién tiene derecho a utilizar la parresía?, ¿es un derecho civil de todos los ciudadanos?, ¿sólo se les garantiza a algunos ciudadanos según su status social o virtudes personales?

Se manifiesta una discrepancia entre un sistema igualitario y la necesidad de escoger a los que beneficien verdaderamente a la ciudad. La igualdad de todos los ciudadanos ante la ley (isonomía) y el derecho legal dado a todo el mundo de decir su propia opinión 
(isegoría) ya no son tales. Tampoco la parresía estaba definida claramente en términos institucionales: no había ley para proteger el parresiastés de represalias o castigos, ni leyes sociales, políticas o institucionales que determinen quién es capaz de decir la verdad. La parresía no es considerada suficiente en sí misma y por sí misma para revelar la verdad. La verdad no puede establecerse a partir de la pura franqueza o coraje absoluto, se requiere de educación o algún tipo de formación profesional. Otro problema sería el tipo de formación personal o educación requerida. "La crisis de la parresía surge en la relación democracia y una interrogación sobre la verdad" (2004, p. 107) de donde se originan una problematización de relaciones entre libertad, poder, democracia, educación y verdad en Atenas a finales del siglo $\mathrm{V}$.

La crisis la origina la forma como es entendida la libertad de palabra. La parresia en sentido negativo es una evidente consecuencia de esta problematización, el partido aristocrático, aprovechando la crisis democrática será el protagonista de las más duras críticas a sus oponentes las demócratas durante la revolución antidemocrática del 411 A.C., durante la guerra del Peloponeso. La parresía negativa puede ser un resultado de la franqueza al hablar, en lugar de la verdad, podría resultar el atrevimiento ignorante que es peligroso para la democracia. Pero como en la democracia todos tienen libertad de palabra, los más corrientes, los peores ciudadanos, no pueden expresar lo mejor para la ciudad. No importa si hablen bueno o malos ciudadanos, cualquiera que hable lo hará a favor de su grupo y no del pueblo.

Basándose Foucault en el Libelo anónimo del Pseudo Jenofonte o el Viejo Oligarca y en el Areopagítico de Isócrates de mediaos del siglo IV, sustenta el conflicto de la parresía con la libertad de palabra y la democracia. Isócrates dice que la parresia en su sentido positivo, crítico, no existe donde existe la democracia, porque sólo se escucha a los oradores depravados o aduladores, que son aceptados por el pueblo, sólo dicen lo que el pueblo desea oír. Pero la voluntad del pueblo y los mejores intereses para la ciudad no coinciden en la democracia, ya que no es posible que se escuche al orador honesto, "que tiene la capacidad de enfrentarse al demo y es bastante valiente como para hacerlo" (2004, p. 116), que además tiene un papel crítico y pedagógico para transformar la voluntad de los ciudadanos para que sirva a los intereses de la verdad. 
La parresia filosófica o parresia socrática, la sustenta Foucault en el Laques de Platón. El cuidado de sí socrático es promover un cambio vida (conversión) a partir de la evaluación de sí mismo (cómo se está viviendo y cómo se ha vivido). Sócrates pide el relato racional de la vida de una persona, para establecer la relación entre el logos y el bios de aquellos que entran en contacto con él. El cambio de vida debe vincular el decir, con el ser y el hacer. "Uno es lo que dice y hace lo que es". Del examen de uno mismo debe surgir el cambio de vida. El discurso racional (logos) debe dar forma al modo de vida (bios).

Mientras que la parresía política es una relación del ciudadano con el demos, la asamblea o la monarquía, es decir en el ámbito de las instituciones políticas en donde se relacionan logos, verdad, valor y nomos, la parresía socrática se da en la relación personal entre dos seres humanos en oposición a la propia ignorancia o a la falsa enseñanza de los sofistas, en donde se interrelacionan logos, verdad, valor y bios, en donde se trata de convencer a alguien a cambiar de modo o estilo de vida.

La parresía socrática se caracteriza por realizar las siguientes actividades:

- Epistémica $\times$ descubrir y enseñar ciertas verdades sobre el mundo, la naturaleza.

- Político ${ }^{\boldsymbol{x}}$ actitud hacia la ciudad, las leyes y las instituciones políticas.

- Estética de sí mismos ${ }^{\boldsymbol{x}}$ explica la naturaleza de las relaciones entre la verdad y el estado de vida.

La parresia filosófica es una práctica (como logos) que intenta dar forma a las relaciones específicas que los individuos tienen consigo mismo (bios).

Para Foucault, esta es la base de nuestra subjetividad moral. La parresía es un modo de vida o estilo de vida que lucha por la verdad, no se somete al discurso ni a su poder, por ello quien cuida de sí mismo es un insurrecto. Este modelo de conducta busca crear nuevos espacios de diálogo frente a las relaciones de poder establecidas.

Foucault ve en la parresía un mecanismo político de gran interés desde una perspectiva ética necesaria para llevar a cabo la praxis política. La parresía que alcanza la praxis política y la cualidad moral, el ethos, al autodominio, no es una vuelta a los griegos, sino un 
punto de partida para una nueva moral, en donde se conjugan la libertad de expresión y la justicia en la sociedad democrática.

\section{Referencias}

Foucault, Michel (2004). Discursos y Verdad en la Antigua Grecia. Barcelona, España: Edición Paidós Ibérica.

(1976). Las palabras y las cosas (una arqueología de las ciencias humanas). México: Siglo Veintiuno Editores.

(1979). Microfisica del Poder. Madrid: La Piqueta.

(1978). Nacimiento de la Biopolítica. En Archipiélago, 30, 119-124.

(1991). ¿Qué es la ilustración? Madrid: La Piqueta. 
